\title{
\begin{tabular}{l|l} 
Mibraries & DSpace@MIT
\end{tabular}
}

\author{
MIT Open Access Articles
}

Mapping complexity sources in nuclear power plant domains

The MIT Faculty has made this article openly available. Please share how this access benefits you. Your story matters.

Citation: Sasangohar, Farzan et al. "Mapping Complexity Sources in Nuclear Power Plant Domains." Proceedings of the Human Factors and Ergonomics Society Annual Meeting, September 2010, vol. 54 no. 25, 2169-2173.

As Published: http://pro.sagepub.com/content/54/25/2169.abstract

Publisher: Human Factors and Ergonomics Society

Persistent URL: http://hdl.handle.net/1721.1/67721

Version: Author's final manuscript: final author's manuscript post peer review, without publisher's formatting or copy editing

Terms of use: Creative Commons Attribution-Noncommercial-Share Alike 3.0 


\section{Mapping Complexity Sources in Nuclear Power Plant Domains}

Understanding the sources of complexity in advanced Nuclear Power Plant (NPP) control rooms and their effects on human reliability is critical for ensuring high and safe performance of both operators and the entire system. New generation control rooms will rely more heavily on automation and computerized $\mathrm{Hu}-$ man-System Interfaces (HSI). Without proper management, information representation and required operator-system interaction could challenge operator information processing capabilities. This paper provides an initial step in assessing the sources of complexity in the NPP control rooms and introduces a systemstheoretic descriptive model of these sources of complexity leveraging network theory.

\section{INTRODUCTION}

The nuclear power industry in United States has declined in terms of growth after the Three Mile Island (TMI) incident in 1979 (Campbell, 1988) (Figure 1). The nuclear community in the United States is now at a stage where existing NPP control rooms are undergoing extensive modernization. Modernization in other supervisory control domains, such as Air Traffic Control (ATC) and cockpit design, has shown an increasing trend in the adoption of digital displays. However, this trend towards "glass cockpits" does not guarantee reduced operator workload or increased performance, since poor information representation can lead to poor operator performance (Wiener and Nagel, 1988; Woods, 1995; Flach et al., 1995).

Personnel in these supervisory control environments must deal with increasing amounts of information and complexity enabled by advanced technologies, such as large digital screens and multiple displays. Unfortunately, there is a lack of consensus among researchers concerning the exact factors that contribute to complexity in these environments, particularly NPP control rooms. Without proper understanding and management of the complexity sources in these control room environments, such complexities may negatively affect human, and ultimately system performance. Poor human performance and errors are costly and not acceptable in such safety-critical work environments.

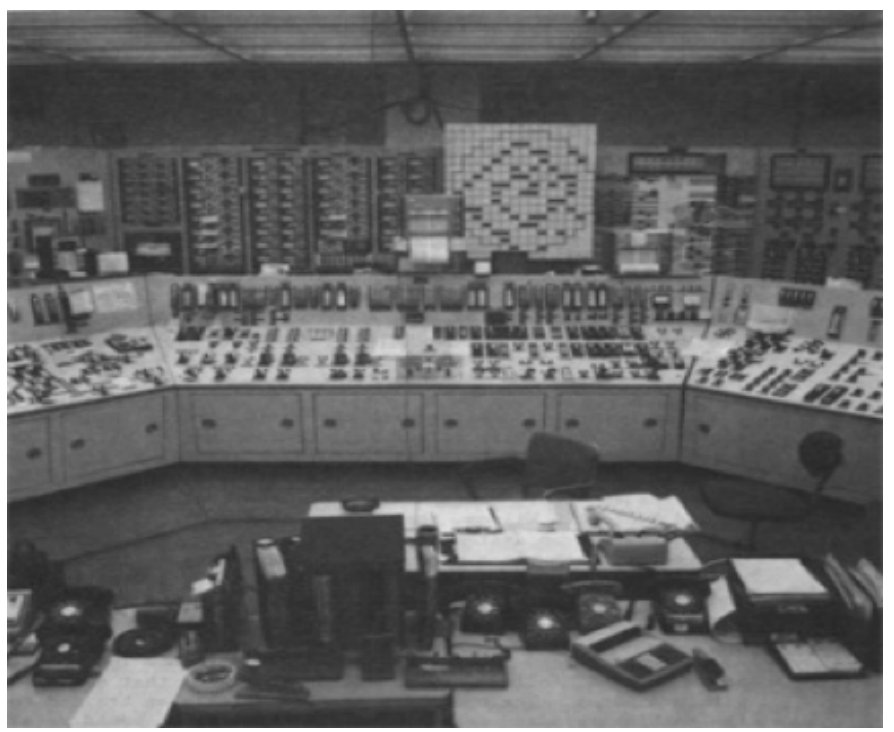

Figure 1. Three Miles Island control room (Kenemy, 1979, p.112).
This paper introduces efforts to identify sources of complexity in NPP control rooms. First, a general definition of complexity is presented and several perspectives on the concept of complexity are introduced. Next, a qualitative approach taken to gather NPP domain information is discussed, and a list of sources of complexity in NPP control room is presented. Lastly the interaction between these sources is discussed.

\section{WHAT IS COMPLEXITY?}

The term "complexity" comes from the Latin word "Complexus", which means "to twine" as defined in the Merriam-Webster dictionary. In general, complexity refers to the difficulty of understanding a phenomenon in the environment. More specifically, we are concerned with complex systems, which include complicated interactions between different system parts. Complexity is defined in various ways across diverse disciplines and in relation to various systems. Although there are many convincing definitions of complexity, there is little consensus on the exact meaning of the term (Edmonds, 1995). Some of the most-used definitions of complexity are often tied to a collection of interconnected parts, or so called "systems". Some give emphasis to the complexity of a system's behavior, while others focus on the internal structure of the system. Simon argues that understanding complexity is only achievable by explaining the system as a tree-structured hierarchy (Simon, 1996).

In many of these definitions, however, complexity in human-system interfaces (HSI) contains several common components. In particular, complexity has been defined in terms of three separate dimensions within a particular system: quantity, variety, and interconnections (Xing and Manning, 2005; Xing, 2007). Quantity refers to the number of items in a certain part of the system. This quantity could be, in the context of HSI in NPP control rooms, the number of displays in the control room, the number of buttons on a control panel, number of icons on a particular display, or the number of sub-systems within an overall system. Variety is the number of different components in the system. Variety could refer to the number of different kinds of buttons on an NPP control panel, the number of different colors in a particular display, the number of different size displays, or the number of different types of pumps in a system. Interconnections describe the links between components of a system. These interconnections can be difficult to quantify in a given system, unless all system states 
are known. For instance, increasing the temperature of water in a holding tank could cause an automatic increase in the flow rate from the tank to a heat exchanger. This "cause and effect" type of interconnection is just one example of the various couplings and links that can occur in a given system.

\section{COMPLEXITY IN SAFETY-CRITICAL ENVIRONMENTS}

NPP control rooms have many elements in common with other human supervisory control systems, thus it is conceivable that complexities in NPP control rooms may share commonalities with sources in other supervisory control systems. Cummings and Tsonis (2006) proposed a Human Supervisory Control (HSC) complexity chain in an effort to isolate specific categories of complexity sources within HSC socio-technical systems, in particular the air traffic control domain (Figure 2). The HSC complexity chain identifies environmental complexity as the objective state of complexity that exists in the world and cognitive complexity as the complexity perceived by a human operator. In the case of a complex environment (NPPs, for example), perceived complexity could be quite high, potentially negatively impacting safe operator performance. For example, many NPPs have redundant systems for safety reasons. However, including a redundant system could double the amount of information available to the operator (including displays and controls), which could increase an operator's cognitive complexity. To mitigate cognitive complexity, organizational policies and procedures along with information representations in the form of interfaces and displays, can be introduced into the system. However, the introduction of these mitigations and devices also can add to the overall perceived complexity of the operator.

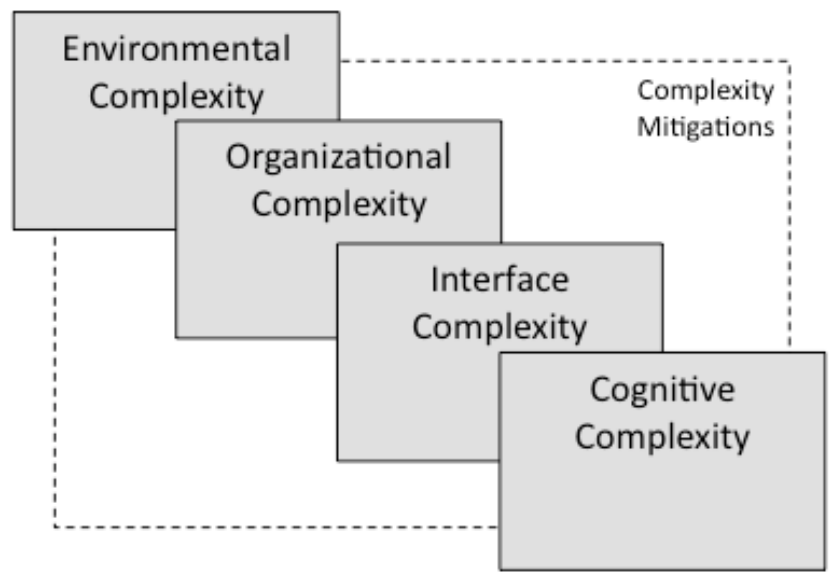

Figure 2. Modified Human Supervisory Control complexity chain, adapted from Cummings and Tsonis, 2006.

Organizational complexity represents the additional constraints placed upon the system by operational requirements, such as the number of crewmembers in the control room, emergency procedures, or shift length. The original HSC complexity chain contained a display complexity category, which considered the complexities offered by visualizations found in the display. This interpretation only recognizes the output to the operator, with no consideration of input from the operator to the system, which is required to close the supervisory control loop. Thus, we propose to change display complexity in the original HSC complexity chain (Cummings \& Tsonis, 2006) to interface complexity, to reflect this two-way communication. Interface complexity is the complexity derived from controls and displays, which could include display font size, number of colors used in the display, or numbers and variety of buttons, levers, etc.

Though this complexity model is representative of many types of complexity within HSC systems, it does not specify the sources of complexity within these systems. The following section identifies and discusses sources of complexity, relating each to the context of nuclear power plant control.

\section{SOURCES OF COMPLEXITY}

Identifying sources of complexity in NPP control rooms is an important first step in understanding the effect (both positive and negative) that particular complexity sources have on control room operation and safety. These sources of complexity can be identified through a series of qualitative methods, including interviews with control room operators, control room observations, field studies, ethnography and cognitive task and work analyses. Our approach focuses on identifying particular sources of complexity within each of the complexity categories described in the HSC complexity chain.

Reviews of previous research in the aviation and process control environments, as well as field studies and operator interviews, led to the initial identification of important sources of complexity in NPP control rooms. In addition, extensive interviews were conducted with personnel in the Massachusetts Institute of Technology (MIT) research reactor in order to gather domain information. Plant operations at several different facilities were observed, including the U.S. Nuclear Regulatory Commission (NRC) Technical Training Center simulator and the New York Independent Systems Operator (NYISO) electricity distribution control room. Additionally, the NRC-maintained Human Event Repository and Analysis (HERA) database was parsed for complexity-related operator mistakes and errors. The review of the HERA database revealed several additional important sources of complexity

In order to verify and validate the identified sources of complexity in the NPP domain, several domain experts were asked to review the complexity sources. In addition, a questionnaire was designed to obtain data from operators in terms of what they perceived as contributors to their job complexity. The design of the questionnaire was informed by the work done by Xing (2008) that evaluated display complexity in air traffic control displays. The questionnaire was tailored to better understand complexity in the NPP environment, and was used to gather data from operators in different control rooms around the world. The questionnaire is a combination of closeended (e.g., likert-scale) and open-ended questions to enable both quantitative analysis and subjective opinion gathering. This data collection effort is still underway.

The qualitative analysis of gathered data led to the generation of an initial list of complexity sources in the NPP control rooms, within the complexity categories of environmental 
(Table 1), organizational (Table 2), interface (Table 3), and cognitive (Table 4). It is notable that the majority of sources can be categorized under quantity and variety, which represent two dimensions of complexity (Xing and Manning, 2005). The third dimension of complexity, interrelationships, is addressed in the next section.

Table 1. Sources of environmental complexity in NPP control rooms.

\begin{tabular}{|l|l|}
\hline \multicolumn{2}{|c|}{ Environmental Complexity } \\
\hline $\begin{array}{l}\text { - Control room size } \\
\text { - Operational mode duration }\end{array}$ & $\begin{array}{l}\text { - Control room layout } \\
\text { - Frequency of operational }\end{array}$ \\
$\begin{array}{l}\text { mode transitions } \\
\text { - Number of operational mode } \\
\text { transitions }\end{array}$ & $\begin{array}{l}\text { Number of critical events in } \\
\text { pumber of external interrup- } \\
\text { tions }\end{array}$ \\
\hline
\end{tabular}

Table 2. Sources of organizational complexity in NPP control rooms.

\begin{tabular}{|c|c|}
\hline \multicolumn{2}{|c|}{ Organizational Complexity } \\
\hline $\begin{array}{l}\text { - Number of procedures } \\
\text { - Variety of procedures } \\
\text { - Number of steps in procedures } \\
\text { - Number of procedure switches } \\
\text { - Number of dependent proce- } \\
\text { dures } \\
\text { - Number of parallel procedures } \\
\text { - Number of required inferences } \\
\text { - } \text { per procedure } \\
\text { Shift length }\end{array}$ & $\begin{array}{l}\text { - Number of crew members } \\
\text { - Number of team hierarchy } \\
\text { levels } \\
\text { - Number of collaborative proce- } \\
\text { dures } \\
\text { - Number of crewmembers re- } \\
\text { quired for each procedure } \\
\text { - Number of information sources } \\
\text { per inference } \\
\text { - Procedure durations } \\
\text { - Duration between procedures }\end{array}$ \\
\hline
\end{tabular}

Table 3. Sources of interface complexity in NPP control rooms.

\begin{tabular}{|l|l|}
\hline \multicolumn{2}{|c|}{ Interface Complexity } \\
\hline - Number of displays & - Real-time update rate \\
- Display size & - Number of animated display \\
- Information amount & features \\
- Variety of fonts & - Number of required unit con- \\
- Font size & versions \\
- Number of icons & - Variety of displays \\
- Variety of icons & - Number of redundant displays \\
- Variety of colors & - Number of control devices \\
- Number of alarms & - Variety of control devices \\
- Variety of alarms & - Number of redundant control \\
- Alarm duration & devices \\
- Display resolution & - Distance between control de- \\
- Number of shared control & vices \\
- devices & - Distance between displays \\
- Number of shared displays & - Distance between control de- \\
- Clutter & vices and displays \\
- Text to graphic ratio & Distance between controls and \\
- Refresh rates & their associated displays \\
\hline
\end{tabular}

Table 4. Sources of cognitive complexity in NPP control rooms.

\begin{tabular}{|l|l|}
\hline \multicolumn{2}{|c|}{ Cognitive Complexity } \\
\hline $\begin{array}{l}\text { - Cognitive fatigue } \\
\text { - Number of years of experience }\end{array}$ & $\begin{array}{l}\text { Number of years of working } \\
\text { in other control rooms }\end{array}$ \\
$\begin{array}{l}\text { with same crew (team famili- } \\
\text { arity) } \\
\text { in same control room }\end{array}$ & $\begin{array}{l}\text { Number of simulator hours } \\
\text { completed per operator } \\
\text { Boredom }\end{array}$ \\
\hline
\end{tabular}

Some of the identified sources in Table 1 are associated with operational modes. An operational mode at any given time could be defined in terms of the reactor's status. Through operator interviews and observations, four modes were identified: monitoring, normal, urgent and emergent. Broadly stated, monitoring and normal modes are associated with low cognitive workload whereas urgent and emergent modes usually involve high cognitive workload. In addition, monitoring and normal modes are related to boredom, which is due to underarousal, caused by insufficient workload (Pattyn et al., 2008). Although fatigue and boredom are highly interconnected, cognitive fatigue, which is caused by high mental effort, could be associated with urgent and emergent modes.

\section{COMPLEXITY SOURCE NETWORK}

One problem that can be seen on inspection of the sources of complexity in Tables 1-4 is the lack of explicit representation of interconnections between these sources. We propose that the interconnections between NPP sources of complexity can be represented and explored via a network representation. The Complexity Source Network (CSN) represents the basic sources of complexity (nodes) within the NPP control room and the interactions that the sources share with one another (connections). Figure 3 shows this network embedded in the categories of the HSC complexity chain. The identification of interactions between the sources is important in order to understand the overall complexity of the NPP control room environment, and sheds some light on the nature of coupling between individual sources. Visualizing the sources within the HSC complexity chain helps identify the connections between the complexity categories as well as isolating the sources in different complexity levels. Domain expert knowledge and operator interviews were used to identify the possible interconnections. The resultant list of interconnections is a large set of pair-wise connections, each of which is represented by a connection within the CSN.

The particular CSN in Figure 3 was generated from the list of complexity source connections using the GUESS (Ey$\tan , 2007)$ visualization software package. There are several methods to analyze networks like the CSN, the simplest of which is identifying those nodes that have the greatest number of connections (or edges). The number of edges a particular node has is related to the relative importance of the complexity source in the control room. Thus, the more edges a node has, the higher chance the source has to impact safe plant operation. In this particular $\mathrm{CSN}$, the node with the greatest number of connections is Cognitive Fatigue, with 22 connections to other nodes (Figure 4). Cognitive Fatigue has the greatest number of connections most likely because of its ability to have a detrimental effect on many activities that need to happen in the control room, especially in urgent or emergent situations (van der Linden et al., 2003). Cognitive fatigue is a prime example of the complex interactions that exist in a NPP control room in that cognitive fatigue can be viewed as the result of some complexity sources, as well as a source of complexity itself.

The CSN can also be analyzed as a whole in terms of the number of nodes and number of edges. In this CSN, there are 


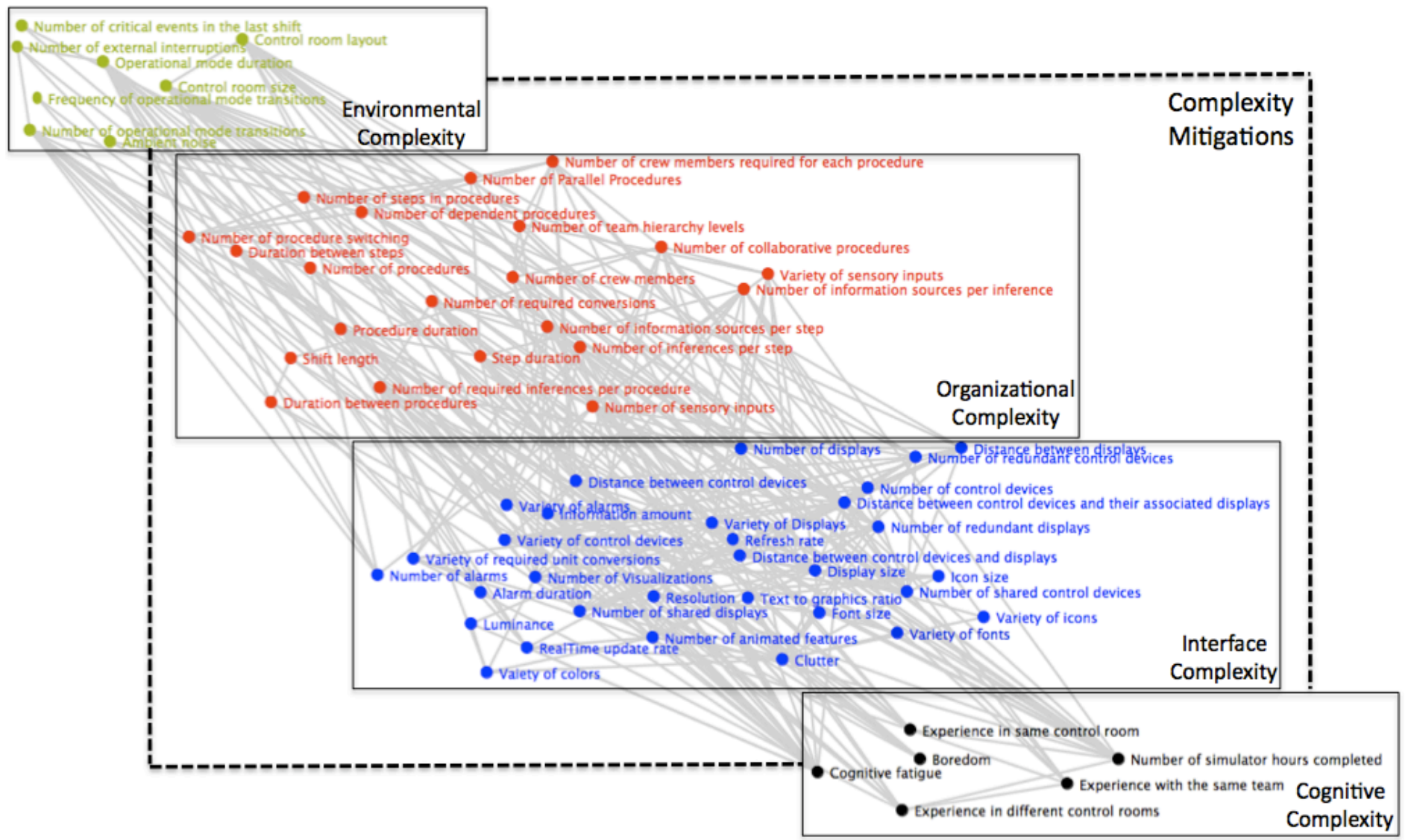

Figure 4. Complexity Source Network grouped by HSC complexity chain categories.

66 individual nodes interconnected with 306 edges. The number of individual components and their connections has been described as a direct measure of complexity (Edmonds, 1995). The edge to node ratio is 4.64 , indicating that on average each node is expected to be connected to roughly 4 or 5 other nodes

- Operational mode duration

- Number of operational mode transitions in the network. This ratio also indicates that any given complexity source has the potential to impact four to five other sources in the control room, conceivably impacting performance in an un-isolated fashion.

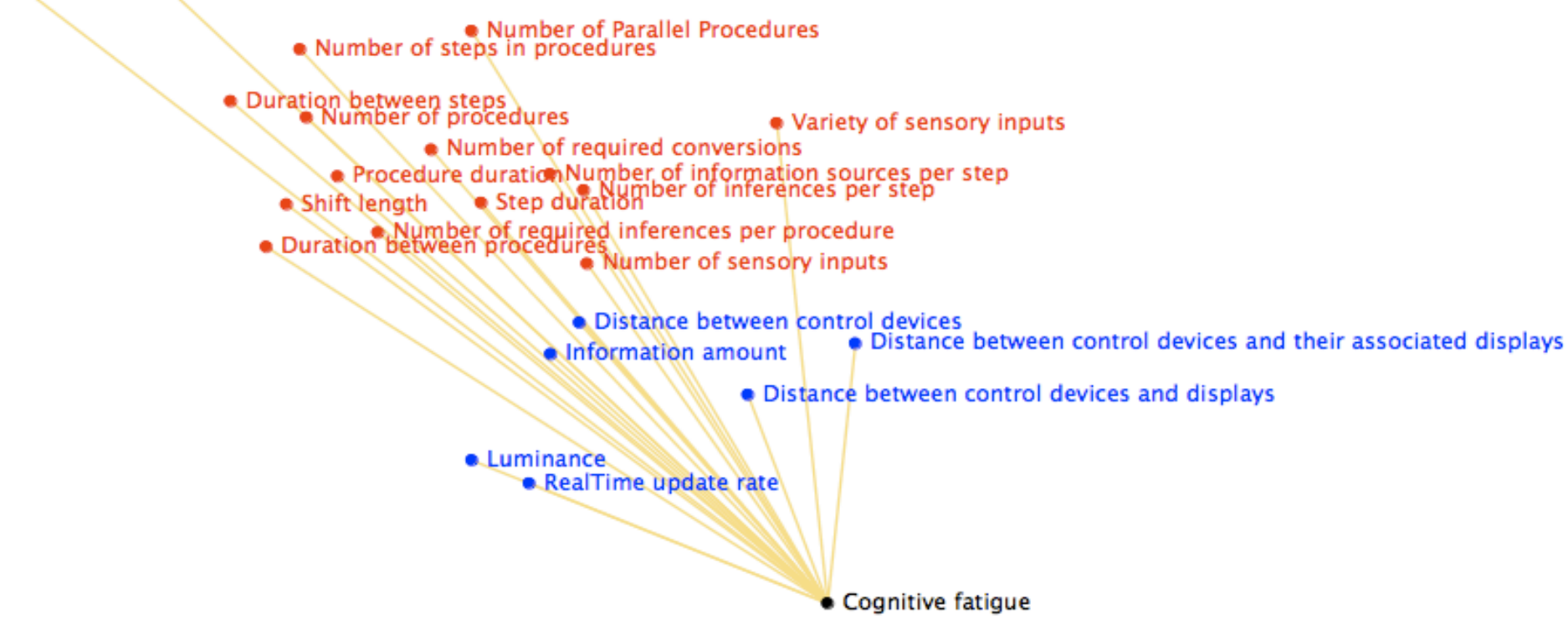

Figure 3. Connections to Cognitive Fatigue from the CSN. 


\section{DISCUSSION}

Identifying sources of complexity within safety-critical environments, such as nuclear power plant control rooms, is important for several reasons. Understanding the effect complexities can have on human behavior and decision-making is key to ensuring safe operation of a plant. Without proper management of these sources, negative effects from each source could potentially propagate to the whole system through complicated interconnections, as illustrated in the CSN. This understanding will also allow the creation of tools or mitigations to support safe plant operation and allow more informed adoption of advanced technologies.

Several sources of complexity and their interconnections were identified using various qualitative data gathering techniques. This analysis led to the development of a Complexity Source Network representation that can be used for additional analysis of system in terms of reducing the unnecessary coupling between the sources. A basic analysis conducted on the preliminary CSN for NPP control rooms suggests that operators' cognitive fatigue is a major contributor to cognitive complexity in the control room. If cognitive fatigue was completely removed from the CSN, the number of edges would be reduced to 284 , the number of nodes reduced by one, and the resultant edge to node ratio would be 4.37 . By removing this one node from the $\mathrm{CSN}$, the ratio would decrease by nearly $6.8 \%$, which would theoretically remove relatively that much complexity from the NPP control room. The idea of removing a node from the network can be extended to all nodes and edges in the network. By systematically identifying sources of complexity that have high impact potential, specific tools and mitigation strategies can be developed to ensure safe human performance in both control rooms and other complex supervisory control systems.

\section{ACKNOWLEDGEMENTS}

This work was sponsored in part by the U.S. Nuclear Regulatory Commission (NRC).

\section{REFERENCES}

1. Campbell, J.L. (1988). Collapse of an Industry: Nuclear Power and the Contradictions of U.S. Policy, Ithaca, New York: Cornell University Press.

2. Cummings, M. L., \& Tsonis, C. (2006). Partitioning Complexity in Air Traffic Management Tasks, International Journal of Aviation Psychology, 16(3), 277295.

3. Edmonds, B. (1995). What is Complexity? - The philosophy of complexity per se with application to some examples in evolution, in F. Heylighen \& D. Aerts (Eds.): The Evolution of Complexity, Kluwer, Dordrecht.

4. Eytan A. and Kim, M. (2007) "SoftGUESS: Visualization and Exploration of Code Clones in Context," ICSE 2007. Retrieved from http://graphexploration.cond.org/

5. Flach, J., Hancock, P., Caird, J., and Vicente, K.
(1995). Global perspectives on the ecology of human-machine systems. Hillsdale, NJ: Erlbaum.

6. Kenemy, J., et al. (1979). Report of the President's Commission on the accident at Three Mile Island. Govt. Printing Office, Washington, D.C.

7. Kumar, A. and Fowler, R.H. (1994). A spring modeling algorithm to position nodes of an undirected graph in three dimensions, NAG9-551-4, Department of Computer Science, University of Texas - Pan American, Edinburg.

8. Laumann, K., Braarud, P.Ø., Svengren, H. (2004). The task complexity experiment 2003/2004. HWR-758. Halden, Norway: Instututt for energiteknikk.

9. Pattyn, N., Neyt, X., Henderickx, D., and Soetens, E. (2008). Psychophysical investigation of vigilance decrement: boredom or cognitive fatigue?, Physiol. Behav., 93, 369-378.

10. Simon, H. A. (1996). "The architecture of complexity: hierarchic systems". In: H. A. Simon (Ed.), The sciences of the artificial, Third Ed., 183-216. MIT Press, Cambridge, MA.

11. van der Linden, D., Frese, M. and Meijman, T.F. (2003). Mental fatigue and the control of cogitive processes: effects on perseveration and planning. Acta Psychologica, 113, 45-65.

12. Wiener, E. L. and Nagel, D. C. (1988). Human Factors In Aviation. San Diego, CA: Academic Press.

13. Woods, D. D. (1995). Toward a Theoretical Base for Representation Design in the Computer Medium: Ecological Perception and Aiding Human Cognition. In J. Flach, P. Hancock, J. Caird, and K. Vicente (eds.), An Ecological Approach To Human Machine Systems I, A Global Perspective. Lawrence Erlbaum, Hillsdale, NJ.

14. Xing, J. (2004). Measures of information complexity and the implications for automation design. Oklahoma, OK: Civil Aerospace Medical Institute.

15. Xing, J. and Manning, C. A. (2005). Complexity and automation displays of air traffic control: Literature review and analysis. Technical Report DOT/FAA/AM-05/4, FAA Office of Aerospace Medicine, Washington, DC.

16. Xing, J. (2007). Information Complexity in Air Traffic Control Displays. Technical Report to Federal Aviation Administration, DOT/FAA/AM-07/26

17. Xing, J. (2008). Designing Questionnaires for Controlling and Managing Information Complexity in Visual Displays. Technical Report to Federal Aviation Administration, DOT/FAA/AM-08/18. 